\title{
On the Intestinal Flora of Bottle-Fed Infant
}

\author{
Tsutomu Yuhara, ${ }^{1 *}$ Satoko Isojrma, ${ }^{1}$ Fumiyasu Tsuchiya, ${ }^{1}$ \\ and Tomotari MitsuokA ${ }^{2}$ \\ Meiji Milk Products Co. Ltd., Research Institute, Higashimurayama-shi, Tokyo 189,1 \\ and Department of Biomedical Science, Faculty of Agriculture, University of Tokyo, Bunkyo-ku, Tokyo $113^{2}$
}

(Received 12 October, 1982)

\begin{abstract}
In order to obtain current information about the intestinal flora of bottle-fed infants, feces from 30 breast-fed infants and 43 bottle-fed infants, including 3 infants of low birth weights, were examined by the method of Mitsuoka. The frequency of occurrence and total number of bifidobacteria in bottle-fed infants were nearly equal to those of breast-fed infants. The number of enterobacteriaceae, streptococci, and anaerobes other than bifidobacteria were significantly higher in bottle-fed infants than in breastfed infants. As for Bifidobacterium species, there was little difference between bottlefed and breast-fed infants in average counts of all the species detected, but the frequency of occurrence of Bifidobacterium bifidum in bottle-fed infants was less than in breast-fed infants. The appearance of bifidobacteria in low birth weight bottle-fed infants was more delayed than that in normal bottle-fed infants, and their species composition was also simple, consisting of two species of bifidobacteria: $B$. breve plus $B$. bifidum, or $B$. breve plus $B$. adolescentis.
\end{abstract}

Key words: Bifidobacterium; bottle-fed infant; breast-fed infant; infant nutrition; intestinal flora

The comparison of intestinal flora of bottle-fed infants with that of breast-fed infants was first carried out by Tissier (12) in 1900, and has been repeated by various investigators $(1-5,7,10,11)$. Most of them reported coliform bacilli, enterococci, and lactobacilli as the predominant organisms of the intestinal flora in bottle-fed infants, whereas bifidobacteria were prevalent in breast-fed infants. The results, however, cannot be applied to the current bottle-fed infants that are fed with improved formulas. The results also had been obtained with study methods which are inadequate by the current standards. Thus, it is desirable to re-examine the intestinal flora of current bottle-fed infants by the advanced study methods. There are only few reports regarding the intestinal flora of low birth weight infants $(6,8)$, and their flora also needs further investigations.

In this study, we examined the intestinal floras of bottle-fed and breast-fed infants, and the transition of intestinal flora along with the growth of bottle-fed infants of low birth weights.

\section{Materials and Methods}

Infants: Table 1 shows the life history of infants that were used in this study. Two of the infants, $A_{1}$ and $A_{2}$, were dizygotic twins of 38 weeks gestation. Their birth weights $(2,560$ and 2,680 g) were much less than the normal weight $(2,800-3,000 \mathrm{~g})$ for a gestation period of 38 weeks. We, therefore, used the infants, $A_{1}$ and $A_{2}$, to see the effects of the low birth weight.

Methods: Intestinal organisms were isolated from the feces of infants by the method 
Table 1. Life history of infants

\begin{tabular}{lccccc} 
& \multirow{2}{*}{ Bottle-fed infants } & \multicolumn{3}{c}{ Low birth weight infants } & \multirow{2}{*}{ Breast-fed infants } \\
\cline { 3 - 5 } & & $\mathrm{A}_{1}$ & $\mathrm{~A}_{\mathbf{2}}$ & $\mathrm{B}$ & \\
\hline Age of infants (days) & $3-134$ & $3-$ & $3-$ & $3-$ & $33-135$ \\
Number of specimens & 40 & 1 & 1 & 1 & 30 \\
Gestation period (weeks) & - & 38 & 38 & 38 & - \\
Birth weight (g) & $3,188 \pm 361$ & 2,560 & 2,680 & 2,360 & $3,208 \pm 348$ \\
Initial feeding & $3-$ Bottle & $3-$ Bottle & $3-$ Bottle & $3-$ Bottle & Breast \\
& Clinic & Clinic & Clinic & Clinic & \\
Place of infants & Infant home & $\downarrow$ & $\downarrow$ & $\downarrow$ & Home \\
& Home & Home & Home & Home & - \\
Period in incubator (days) & - & 1 & 1 & 16 & - \\
Staying period in clinic (days) & - & 7 & 7 & 26 & \\
Weaning age (days) & $\nearrow$ & 153 & 153 & 144 & \\
\hline
\end{tabular}

Table 2. Comparison of fecal flora between bottle-fed infants and breast-fed infants

\begin{tabular}{lcccc}
\hline \multicolumn{1}{c}{ Organisms } & \multicolumn{2}{c}{ Bottle-fed infants } & \multicolumn{2}{c}{ Breast-fed infants } \\
\hline Enterobacteriaceae & $9.5 \pm 0.5^{a}$ & $(100)^{b}$ & $8.6 \pm 1.3^{* *}(100)$ \\
Streptococci & $9.8 \pm 0.6$ & $(100)$ & $7.9 \pm 1.5^{* *}(100)$ \\
Staphylococci & $5.5 \pm 1.7$ & $(100)$ & $5.8 \pm 1.9$ & $(97)$ \\
Lactobacilli & $7.2 \pm 1.5$ & $(78)$ & $6.8 \pm 1.7$ & $(80)$ \\
Bifidobacteria & $10.0 \pm 2.2$ & $(97)$ & $10.7 \pm 0.9 \quad(100)$ \\
Eubacteria & $7.3 \pm 4.1$ & $(78)$ & $3.1 \pm 4.6^{* *}(33)^{* *}$ \\
Bacteroidaceae & $9.9 \pm 1.1$ & $(100)$ & $6.1 \pm 4.3^{* *}(67)^{* *}$ \\
Peptococcaceae & $7.9 \pm 4.0$ & $(80)$ & $2.4 \pm 4.1^{* *}(27)^{* *}$ \\
Clostridium perfringens & $6.4 \pm 2.5$ & $(50)$ & $1.0 \pm 2.3^{* *}(17)^{*}$ \\
Clostridia-other & $0.9 \pm 2.6$ & $(10)$ & $1.3 \pm 3.2$ & $(13)$ \\
Veillonellae & $5.9 \pm 4.6$ & $(63)$ & $5.8 \pm 3.4$ & $(83)$
\end{tabular}

${ }^{a}$ Mean \pm SD of log organism counts. $\quad{ }^{b}$ Frequency of occurrence (\%).

Significant difference: $* * p<0.01 ; * p<0.05$.

Table 3. Comparison of Bifidobacterium species between bottle-fed infants and breast-fed infants

\begin{tabular}{ccc}
\hline Bifidobacterium species & Bottle-fed infants & Breast-fed infants \\
\hline B. bifidum & $9.3 \pm 1.0^{a}(23)^{b}$ & $9.9 \pm 0.6(70)$ \\
B. infantis & $10.2 \pm 0.2(8)$ & $10.6 \pm 0.4(7)$ \\
B. breve & $10.2 \pm 0.7(93)$ & $10.7 \pm 0.7(90)$ \\
B. adolescentis & $9.8 \pm 0.9(53)$ & $9.6 \pm 0.6(40)$ \\
B. longum & $9.5 \pm 0.9(45)$ & $9.6 \pm 0.8(67)$ \\
\hline
\end{tabular}

$a$ Mean $\pm \mathrm{SD}$ of $\log$ bacterial counts. $\quad{ }^{b}$ Frequency of occurrence (\%).

of Mitsuoka (9). Identification of genus of bacteria, and species of bifidobacteria were also done according to Mitsuoka (9).

Statistical analyses on the number and isolation frequency of the microflora were made for the purpose of comparing the flora between experimental groups: The mean difference of bacterial numbers was analyzed by the Student's $t$ test; The frequencies of occurrence were compared by the $\chi^{2}$ test.

\section{Results and Discussion}

Difference in intestinal flora between bottle-fed and breast-fed infants: The number and isolation frequency of the intestinal floral microorganisms of bottle-fed and breast-fed infants are shown in Table 2. The difference in the frequency of occurrence and total number of bifidobacteria between bottle-fed and 


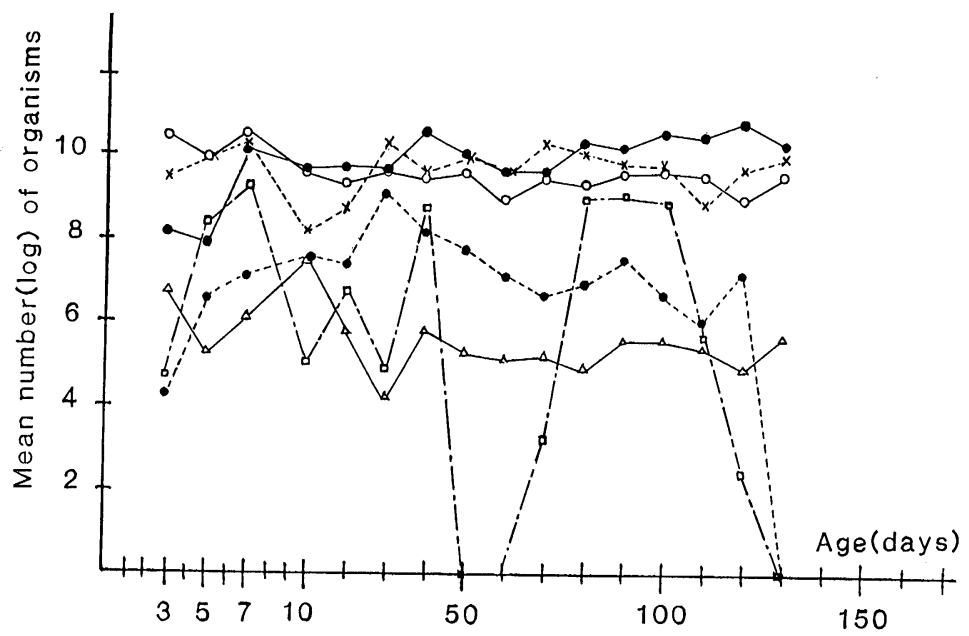

Fig. 1. Changes of fecal flora according to age of bottle-fed infants.

- -: Enterobacteriaceae, - - : bifidobacteria, $-\triangle-$ : staphylococci, -.----: lactobacilli, --- $\times---$ : bacteroidaceae, -- $\square--$ : C. perfringens.

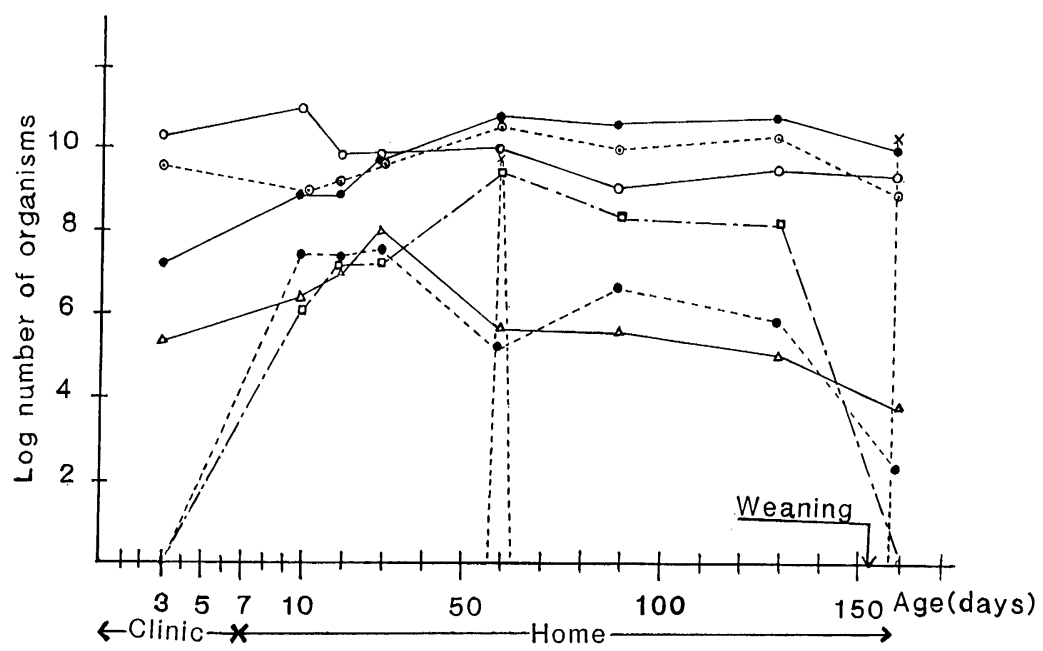

Fig. 2. Changes of fecal flora according to age of low birth weight bottle-fed infant $A_{1}$. - - : Enterobacteriaceae, - - - : bifidobacteria, --- --- : streptococci, $-\triangle-$ : staphylococci, --- -.-: lactobacilli, --- $\times---$ : bacteroidaceae, -- --- : C. perfringens.

breast-fed infants were not significant. The principal difference between bottle-fed and breast-fed infants was that the numbers of enterobacteriaceae, streptococci, and anaerobes other than bifidobacteria in bottle-fed infants were significantly greater than those in breast-fed infants. These results agree with those reported by. Haenel et al. (5). Table 3 shows the difference in Bifidobacterium species composition of intestinal flora between bottlefed and breast-fed infants. The difference in number of each species between bottle-fed and breast-fed infants was not significant, but the frequency of occurrence of $B$. bifidum for bottle-fed infants were less than that for breast-fed infants. Such a high number of bifidobacteria in the recent bottle-fed infants may reflect the improvement of formula 


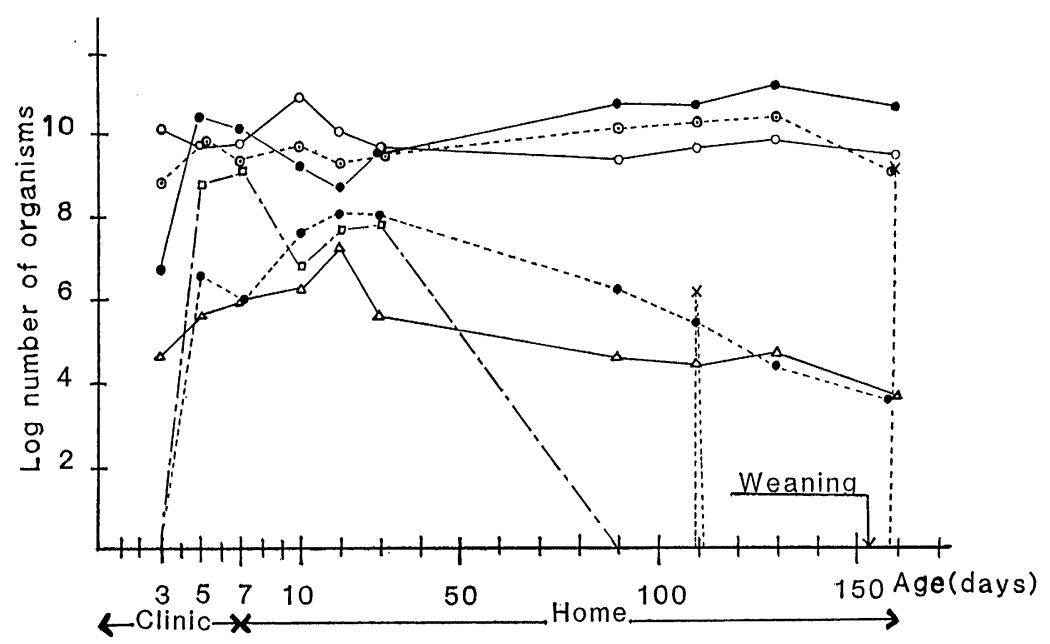

Fig. 3. Changes of fecal flora according to age of low birth weight bottle-fed infant $\mathrm{A}_{2}$. ——: Enterobacteriaceae, - - - : bifidobacteria, --- ---: streptococci, $-\triangle-$ : staphylococci, ------: lactobacilli, --- $\times---$ : bacteroidaceae, -- $\square--$ : C. perfringens.

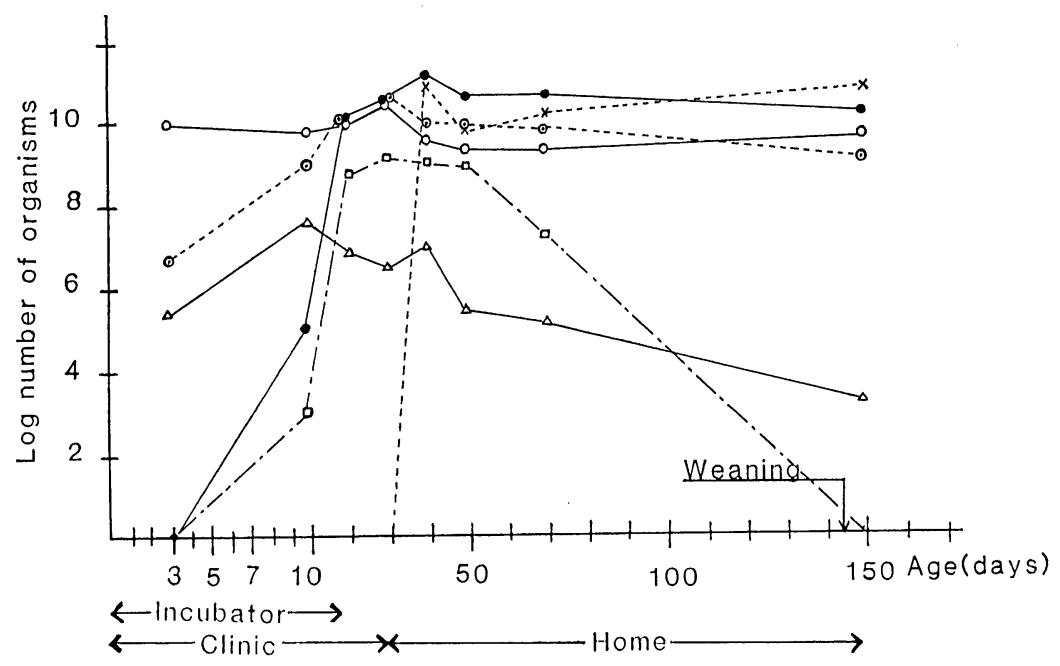

Fig. 4. Changes of fecal flora according to age of low birth weight bottle-fed infant $B$.

- - : Enterobacteriaceae, - - - : bifidobacteria, --- $\odot---$ : streptococci, $-\triangle-$ : staphylococci, $--\times---$ : bacteroidaceae, -- $\square--$ : C. perfringens.

component, i.e., the enhancement of protein digestability, decrease in protein and salt contents, and increase in lactose content.

Intestinal flora of low birth weight bottle-fed infants: In Fig. 1, the counts of fecal organisms of 40 bottle-fed infants are plotted against their ages. The time-courses of the changes of fecal organisms of bottle fed low birth weight infants, $A_{1}, A_{2}$, and $B$, are shown in Figs. 2, 3, and 4, respectively. Bifidobacteria in normal bottle-fed infants gradually increased and they outnumbered Enterobactericeae in 10 days. On the other hand, it took a further 10-20 days for bifidobacteria in the low birth weight bottlefed infants to dominate.

Figure 5 shows the time-course of the changes in Bifidobacterium species of normal 


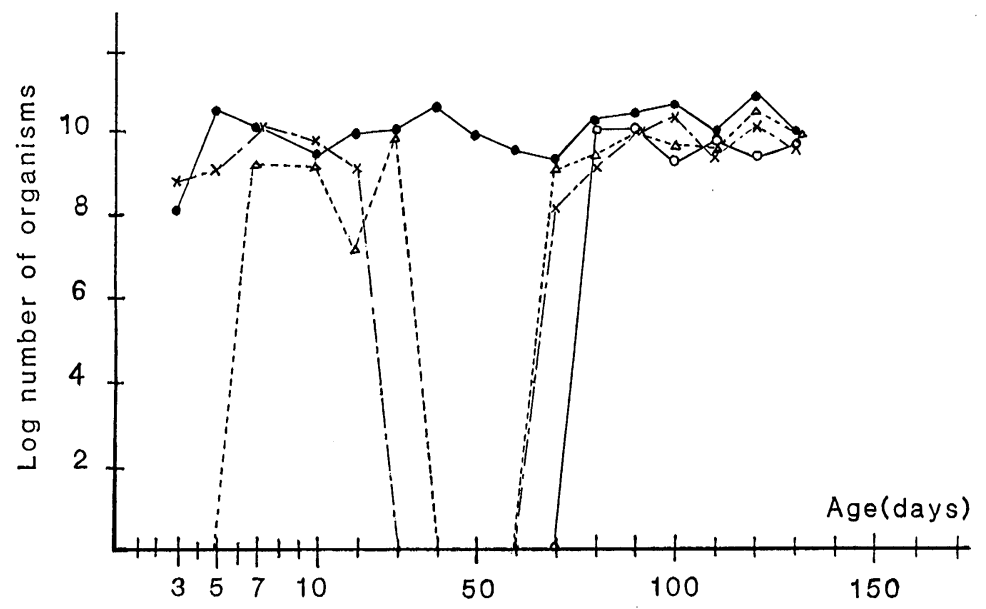

Fig. 5. Changes of Bifidobacterium species according to age of bottle-fed infants.

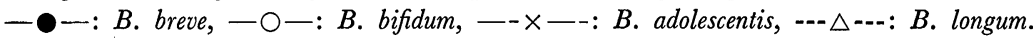

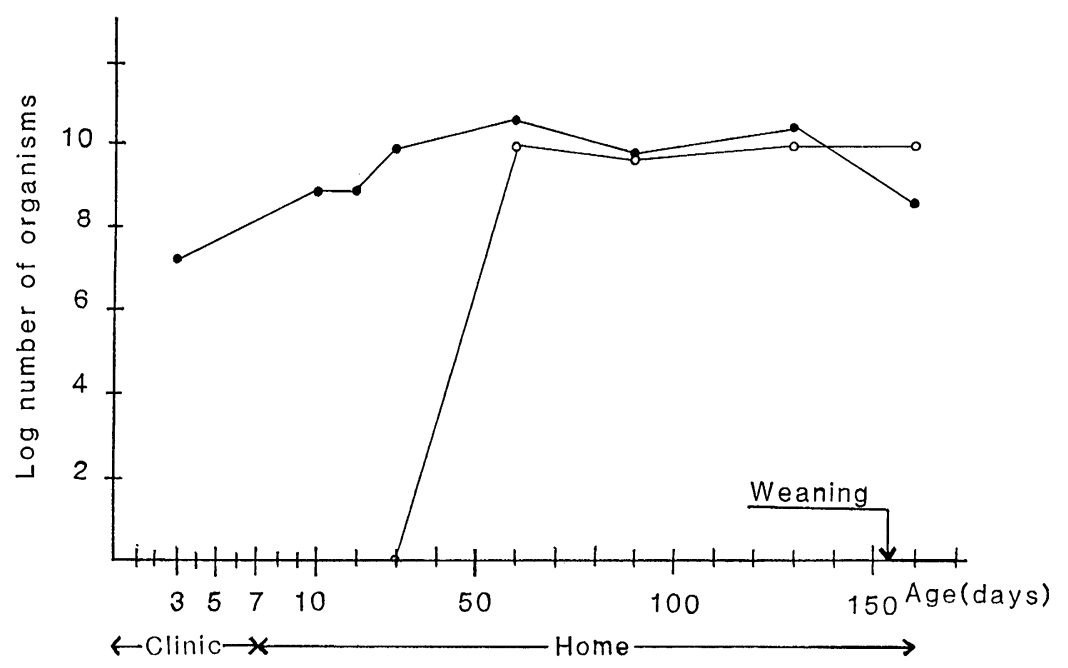

Fig. 6. Changes of Bifidobacterium species according to age of low birth weight bottle-fed infant $A_{1}$.

- - B. Breve, - $\bigcirc-$ : B. bifidum.

bottle-fed infants. Those for low birth weight bottle-fed infants, $A_{1}, A_{2}$, and $B$, are also shown in Figs. 6, 7, and 8.

As is evident from Figs. 6, 7, and 8, the species composition of bifidobacteria of low birth weight bottle-fed infants was simpler than that of normal bottle-fed infants, consisting of only two species. Bifidobacterium breve was detected at first, followed by an appearance of either B. bifidum or B. adole- scentis. The delayed appearance of bifidobacteria might reflect the immaturity of the digestive organs of low birth weight infants.

\section{References}

(1) Adam, A. 1921. Über Darmbakterien. III Über den Einflu der H-Ionenkonzentration des Nährbodens auf die Entwicklung des Bacillus bifidus. Zeit. Kinderheilk. 29: 306-320. 


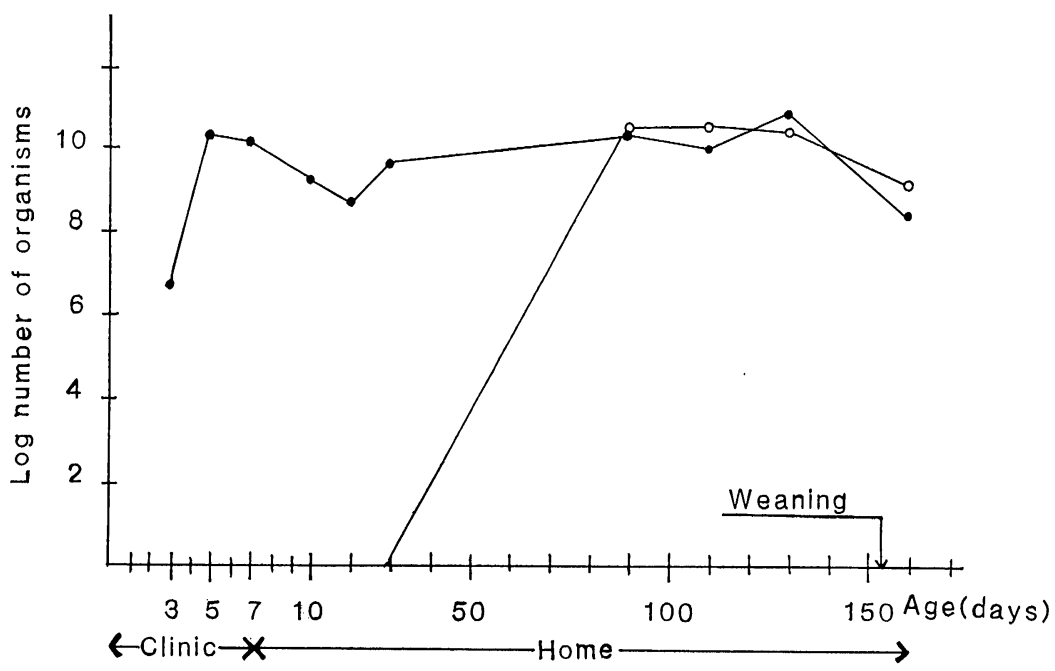

Fig. 7. Changes of Bifidobacterium species according to age of low birth weight bottle-fed infant $\mathrm{A}_{2}$.

- -: B. breve, 一○-: B. bifidum.

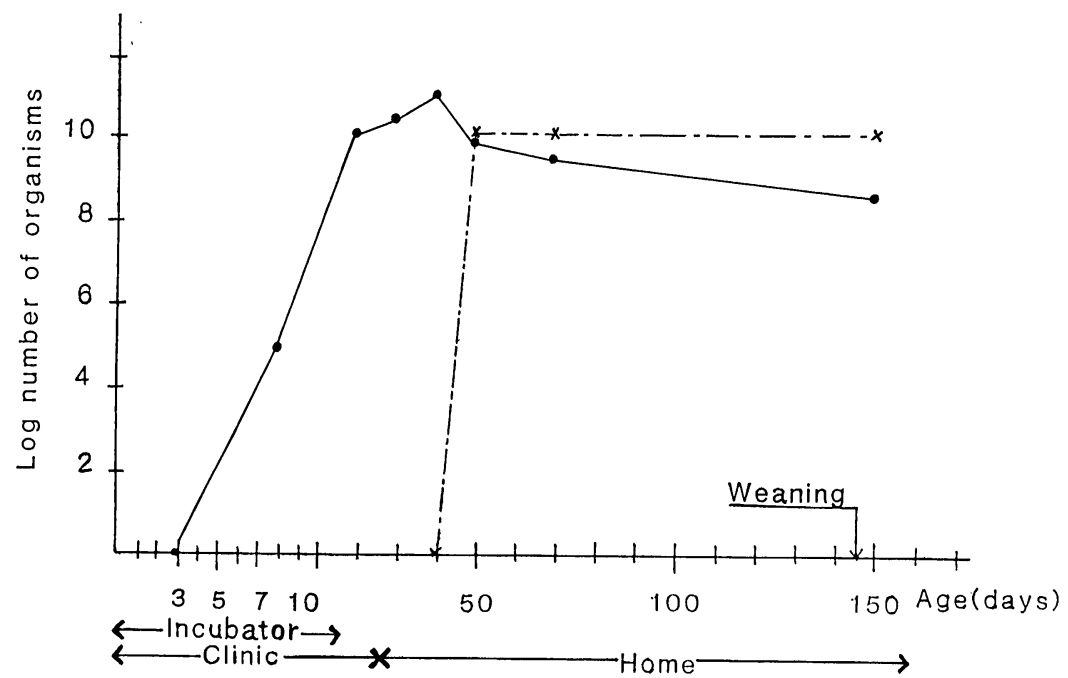

Fig. 8. Changes of Bifidobacterium species according to age of low birth weight bottle-fed infant $\mathrm{B}$.

- - B. breve, -- $\times--:$ B. adolescentis.

(2) Asami, K. 1960. Studies of artificial mothermilk. Acta Paed. Jpn. 64: 562-566.

(3) Boventer, K. 1938. Untersuchungen über das Bacterium bifidum. Zbl. Bakt. I. Abt. Orig. 142: 419-430.

(4) Distaso, A. 1911. Sur les microbes acido-tolérants de la flore intestinale. Zbl. Bakt. I. Abt. Orig. 59: 48-63.

(5) Haenel, H., W. Müller-Beuthow, und F.K.
Grütte. 1970. Zur fäkalen Mikroökologie des Säuglings in Abhängigkeit von der Ernährung: Zusammensetzung der Mikroflora sowie Vorkommen der Lactobacillus bifidus-Typen. Zbl. Bakt. I. Abt. Orig. 215: 333-347.

(6) Imura, S. 1981. Fecal nature and intestinal flora in the low birth weight bottle-fed infant. Jpn. J. Paed. 34: 2295-2303.

(7) Isoda, S. 1966. Studies on the intestinal flora of 
healthy infant. Acta Paed. Jpn. 70: 110-116.

(8) Leuterer, W. 1963. Das Verhalten der Bifidumflora und des Stuhl-pH von Frühgeborenen bei Ernahrung mit Frauenmilch, adaptierter Milch und Verdünnter Kuhmilch. Ann. Paediatr. 200 : 7-19.

(9) Mitsuoka, T., K. Ohno, Y. Benno, K. Suzuki, und K. Namba. 1976. Die Faekalflora bei Menschen. IV. Mitteilung: Vergleich des neu entwickelten Verfahrens mit dem bisherigen üblichen
Verfahren zur Darmfloraanalyse. Zbl. Bakt. Hyg., I. Orig. A 234: 219-233.

(10) Negishi, A. 1958. The study on the intestinal flora of healthy infants. Acta Paed. Jpn. 63: 187195.

(11) Olsen, E. 1949. Studies on the intestinal flora of infants. Munksgaard, Copenhagen.

(12) Tissier, H. 1900. Recherches sur la flore intestinale des nourrisson. Paris. 